\title{
Experimental and theoretical evaluation of the performance of a Whispergen Mk Vb micro CHP unit in typical UK house conditions
}

\author{
A. Alexakis, G. Gkounis, K. Mahkamov ${ }^{*}$, J. Davis \\ School of Computing, Engineering and Information Sciences, Northumbria University, \\ Newcastle upon Tyne, NE1 8ST, UK* \\ *Corresponding author, Tel:+44 191 2274739, Fax: +44 1912437630 , \\ Email: khamid.mahkamov@northumbria.ac.uk
}

\begin{abstract}
A Whispergen $\mathrm{Mk} \mathrm{Vb} 1 \mathrm{KW}_{\mathrm{e}}$ Stirling Engine mCHP unit was integrated into a test rig simulating a typical UK domestic hydronic heating system and tested implementing derived heat demand profiles in the house over the yearly period. The obtained experimental performance was used as input data for static simulations in CANMET Energy RETScreen software to calculate economical and environmental benefits from deployment of the mCHP instead of a condensing boiler. Simulation results show that a $16 \%$ annual monetary savings can be achieved due to the introduction of new UK feed-in tariffs. The payback period when using the mCHP system instead of a condensing boiler is about 8 years. These results can be used for determination of strategy for further improvement of the performance of the unit.
\end{abstract}

Keywords: Domestic mCHP, Fuel combustion, Energy conversion efficiency

\section{Introduction}

mCHP is a promising on-site generation technology which, under particular conditions, can provide energy, carbon and cost savings. The installation of large scale CHP systems (hospitals, airports etc.) has been already proven beneficial due to the high combined efficiency. Those have made the installation of CHP for much smaller applications (domestic) an attractive option and have led to the development of a number of mCHP systems with some being already commercially available.

For small scale domestic applications the Stirling Engine based mCHP systems are considered more suitable due to their quiet operation and high heat/power ratio. The aforementioned, combined with the newly introduced UK feed-in tariff, can have a significant impact on domestic sector carbon emissions and energy consumption.

The scope of this research is to obtain a thorough understanding of the parameters that affect the performance of domestic Stirling Engine mCHP systems and engineer solutions for their feasible deployment. The evaluated deployment scenarios differ mainly in the house size, age and occupancy pattern. These are very important factors which affect the magnitude of the energy demand [1].

\section{Methodology}

\subsection{Experimental Apparatus}

All experiments were carried out with a $1 \mathrm{~kW}_{\mathrm{e}}$ Whispergen $\mathrm{Mk}$ Vb Stirling Engine gas fired unit integrated with a test rig which simulates a conventional hydronic space heating system with four panel radiators. The mCHP unit is equipped with two gas burners; the main burner has a heat generation capacity of $6 \mathrm{~kW}_{\text {th }}$ with no part load operation capability and provides the heat to run the Stirling engine. The auxiliary burner generates an additional $5 \mathrm{~kW}_{\text {th }}$ and its operation is controlled by the system's electronics. A $150 \mathrm{l}$ tank has been retrofitted to the test rig to allow simulation of Domestic Hot Water (DHW) heating-up and consumption. A threeway valve has been installed to split the water circulation to the two water circuits. The 
auxiliary burner is controlled by a Honeywell Outside Temperature Compensator (OTC) sensor. A number of meters are used for data acquisition. These include a gas meter, two ultrasonic heat meters and a data logging system for obtaining the mCHP operating parameters during experimentation via a computer interface. The operation of the mCHP unit is controlled by a programmable thermostat-controller device. Unlike pre-commercial prototype Whispergen Mk III system Mark Vb mCHP system does not have a modulation capability, e.g. it can operate only at a full load or is switched off when the heat demand is satisfied.

\subsection{Experimental Procedure}

The procedure followed for the performance evaluation of the Whispergen $\mathrm{Mk} \mathrm{Vb} \mathrm{mCHP}$ includes dynamic and steady state performance analysis and efficiency calculations and carbon emissions analysis, similar to [2, 3]. Heat demand is modeled by determining an occupancy pattern and programming the thermostat-controller to signal it. For the analysis, data is logged every minute [4]. The most important information is provided by the flow and return temperatures, the power generated and the exhaust temperature. The heat meters installed on the water pipes provide information about the water flow rate and the heat generated by the unit. This is sufficient for steady state efficiency calculations. However, since their output cannot be logged to the computer, the temperatures are taken from the engine log for transient state calculations. Then, the generated thermal energy (in $\mathrm{kWh}_{\text {thermal }}$ ) is calculated as

$Q_{\text {gen }}=\frac{\sum_{i=0}^{n} C p_{\text {water }}\left(T_{\text {flow }}-T_{\text {return }}\right)\left(\dot{m}_{C H}+\dot{m}_{D H W}\right)}{60}$

where $n$ is the cycle duration in minutes, $T_{\text {flow }}$ and $T_{\text {return }}$ are the cooling water outlet and inlet temperatures respectively and $\dot{m}_{C H}$ and $\dot{m}_{D H W}$ are the mass flow rates of the heating and the hot water circuits, respectively.

The heat input to the engine is calculated by recording the fuel consumption and using its Low Heating Value. Then efficiencies are calculated as

$$
n_{\text {thermal }}=\frac{Q_{\text {gen }}}{Q_{\text {fuel }}}
$$

and

$n_{\text {electrical }}=\frac{E_{\text {gen }}}{Q_{\text {fuel }}}$

where $Q_{g e n}$ is the heat generated from the mCHP, $E_{\text {gen }}$ is the electricity generation and $Q_{\text {fuel }}$ is the energy content of the fuel.

The total fuel utilization efficiency is the sum of the thermal and electrical efficiencies.

Another area of interest is the engine's time response to heat demand signals. Therefore, once heat and power generation values have been obtained, they are plotted against time. 


\subsection{Domestic Operation Modeling}

For modeling procedures CANMET RETScreen [5] and EnergyPlus [6] software packages are used in this work. These packages use algorithms based on application of energy balance equations. For example, EnergyPlus uses energy balance equations for a number of zones in the simulated dwelling. Software contains library with a set of material properties used in the structure of the building, data on the climatic conditions and experimental and theoretical correlations to calculate heat losses and the temperature rise inside the house.

Data collected from experiments are used as input to CANMET RETScreen software. This software is a useful tool for comparing a proposed energy plant (mCHP) to a conventional one (grid electricity and gas fired condensing boiler). The user can provide parameters such as the house size and location, the fuel and electricity prices and the operating characteristics of the systems such as their efficiency. Software estimates the annual energy demand and performance of the systems in terms of carbon emissions and economics. There are, however, indications that this software cannot take into account the transient character of the energy demand and of plant operation. Such coarse temporal analyses are likely to lead in overprediction of the systems' performance [7, 8]. Therefore, the results from RETScreen are used for initial estimations. Then, more detailed models are built in EnergyPlus, which is capable of modeling energy performance on a more detailed basis by considering the transient operational states of the systems under investigation. The results from EnergyPlus are validated by comparing theoretical data obtained with information derived from gas and electricity bills for real houses. The modeled houses are of the semi-detached or detached type which represent a large farction of the UK housing stock [9]. The chosen location was London, UK. Electricity demand data and appliance wattage ratings are found in [10]. Finally, the mCHP unit is programmed to run to meet the demand profile generated by the domestic energy modeling process. For example, table 1 presents a mCHP running schedule for a design day during a winter. The operation strategy was based on heat-led mode and focused on minimizing heat generation surplus.

Table 1. mCHP running operation schedule for a typical winter day.

\begin{tabular}{llc}
\hline Type of Day & Weekday & Weekend \\
\hline Morning & 2-hours run & 6-hours run \\
Evening & 6-hours run & 6-hours run \\
\hline
\end{tabular}

\section{Results and Discussion}

The performance of the conventional heating system throughout the year was modeled in EnergyPlus software. The results for a design day during the cold season are presented in Fig. 1. 


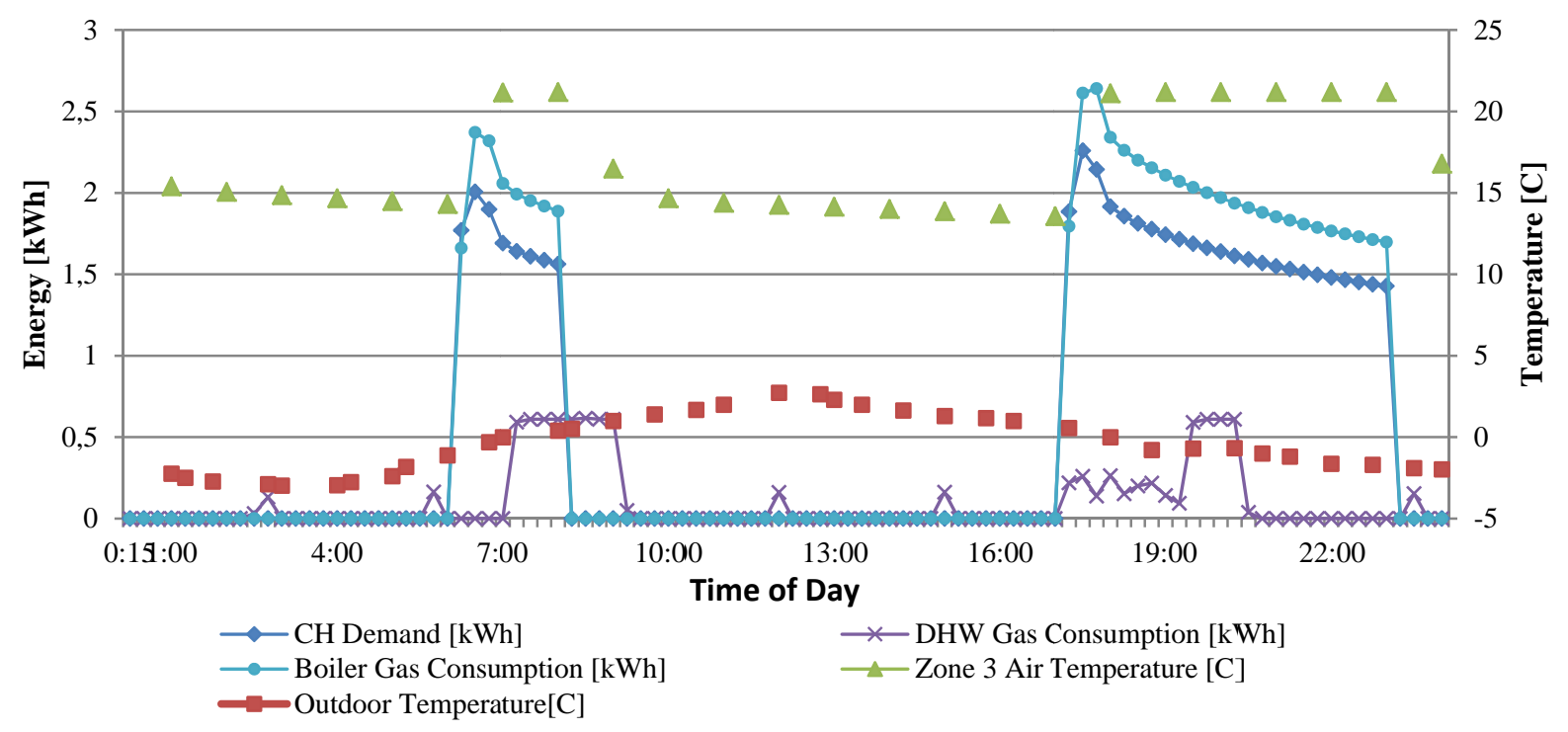

Fig. 1. Demand and temperature profiles on a design day during heating season

It can be seen from fig. 1 that the gas consumption of the heating system decreases as the ambient temperature raises towards midday. The inner temperature increases once the heating system is fired.

The calculated monthly energy demand profiles are presented in fig. 2.

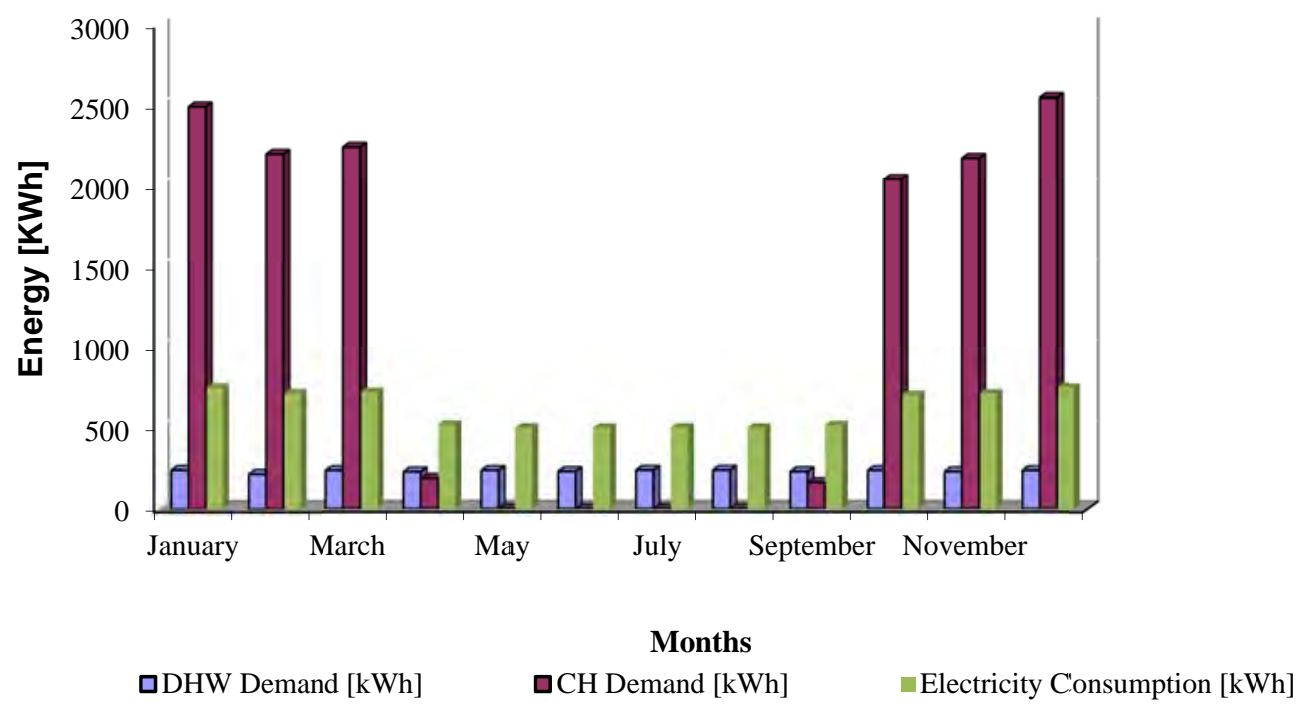

Fig. 2. Calculated monthly energy demand profiles

It can be seen from fig. 2, that simulations reflect that the heating and electricity demands are higher during the heating season. The electricity consumption of the heating system has been included in the monthly electricity demand.

The steady state and cycle electrical and thermal efficiencies of the Whispergen mCHP system have been calculated and are presented in fig. 3 . 


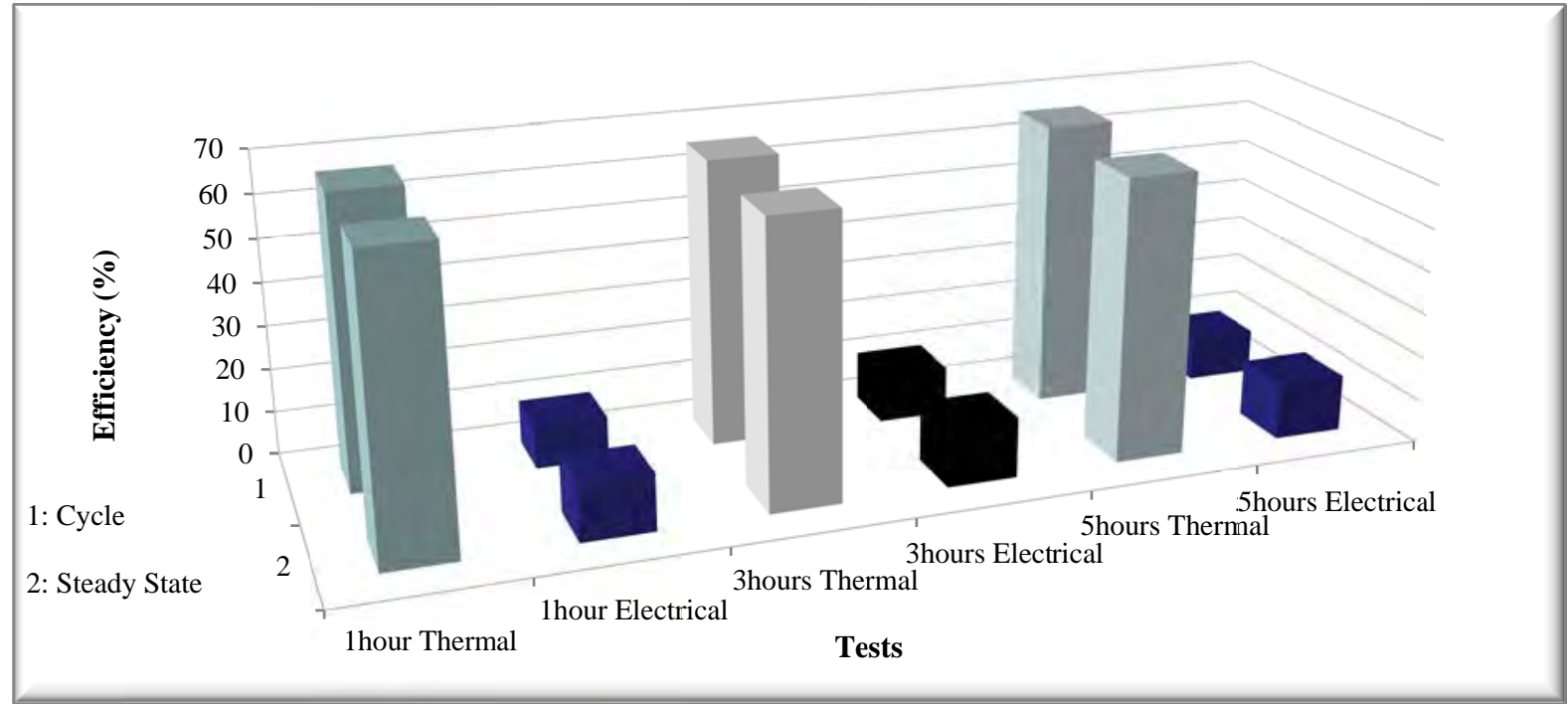

Fig. 3. Steady state and cycle efficiency measurements for different test durations.

It can be observed in fig. 3 that the thermal efficiency is about $66 \%$ for all tests during the steady state operation and for the whole cycle monitoring. The electrical efficiency was found to be about $10 \%$ for the whole cycle measurements and $12 \%$ for the steady state measurements. These values were consistent for all tests. The thermal efficiency of the mCHP has been found to be considerably lower than that of a condensing boiler. This finding is consistent with [11]. In cycle and steady state measurements, the thermal efficiency remained at approximately the same level. This is due to the water circulator pumping water throughout the system after the combustion process has ended to allow more effective cooling of the engine (fig. 5). The cycle electrical efficiency is affected by the dynamic performance during start-up (fig. 4) and is lower than the steady state efficiency. It is believed that this low performance is caused by the lower gas pressure of the working gas inside the Stirling engine. This was a design trade-off to avoid wear of moving parts.

The start-up and rundown characteristics of the Whispergen $\mathrm{Mk} \mathrm{Vb}$ mCHP are presented in fig. 4 and 5, respectively.

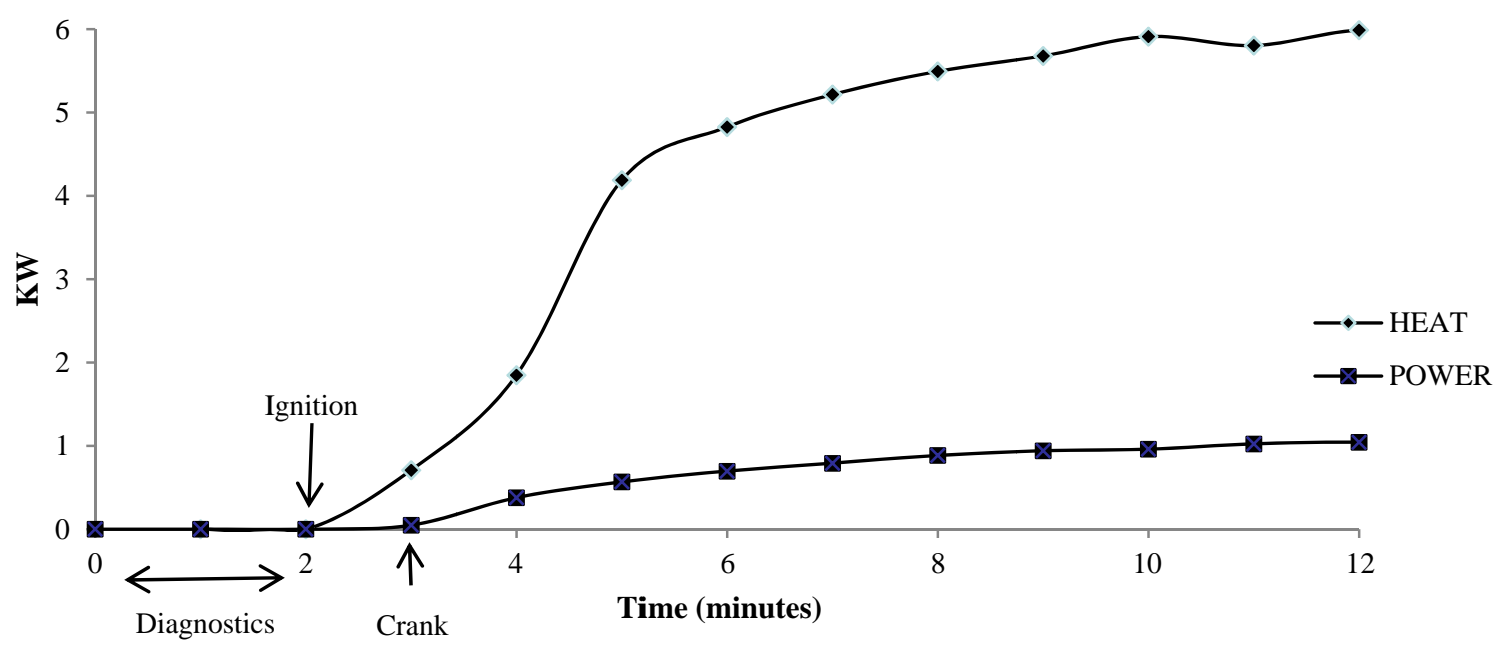

Fig.4. Breakdown of Whispergen Mk Vb start-up characteristic. 


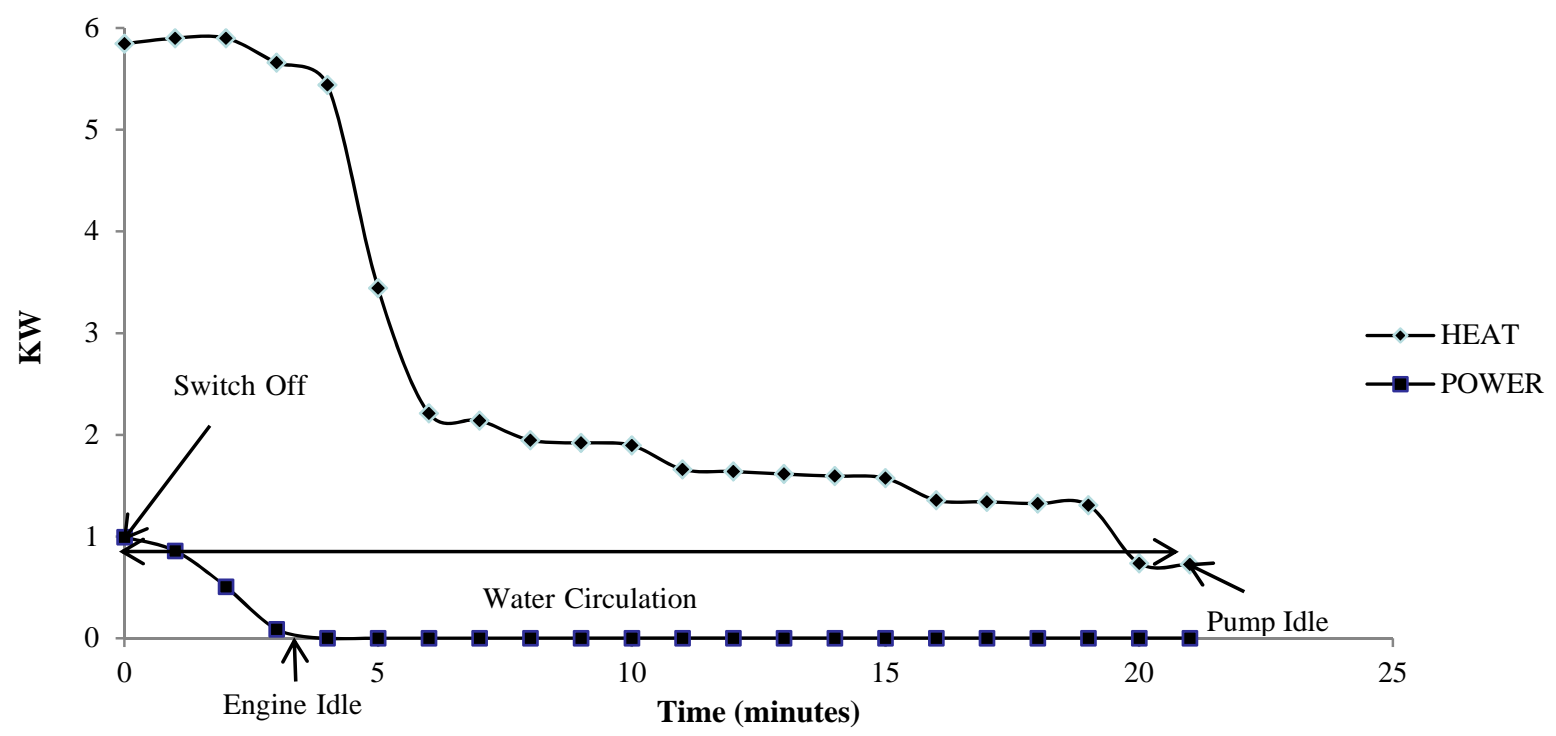

Fig. 5 Breakdown of Whispergen Mk Vb run-down characteristic.

The results presented above were used as input data for RETScreen software and a comparison between the mCHP system and a conventional energy scenario including a condensing boiler and grid electricity was carried out. The results are presented in table 2 for two houses with different heat demands.

Table 2. Annual performance of mCHP compared to a conventional system for 2 houses.

\begin{tabular}{lcc}
\hline House Type & $5 \mathrm{kWth}$ semi -detached & $9.5 \mathrm{kWth}$ detached \\
\hline Annual Benefits & $£-54$ & $£ 87$ \\
Annual carbon savings & $-500 \mathrm{Kg}$ & $300 \mathrm{Kg}$ \\
\hline
\end{tabular}

Results obtained using RETScreen indicated that the particular mCHP system would be unfeasible for a relatively new semi-detached house with a low heat demand. The feasibility of the system was considerably improved for a larger house with a higher heat demand. Similar results can be found in literature [12]; however, different methods and models were used. It is believed that the particular software neglects the transient performance of both the mCHP unit and the heating boiler, as well as the dynamics of domestic energy demand and energy pricing. Furthermore, the estimated electricity demand does not include the electricity consumption of the heating boiler which may add up to the electrical about $10 \%$ of the boiler rated output [11]. Additionally, the software sizes the conventional heating boiler based on solely heat demand $\left(5 \mathrm{~kW}_{\mathrm{th}}\right)$. In reality, this demand would be met by a $15 \mathrm{~kW}_{\text {th }}$ boiler. This over sizing limits the efficiency of the boiler. The software prediction is more encouraging for the detached type house as the mCHP displaces more grid electricity by operating for longer periods to meet the higher heat demand. The economic savings are attributed to the recently introduced feed-in tariff (10 pence per every kWh of electricity) [13] and the carbon savings are associated to the carbon intensity of the displaced grid electricity.

The mCHP was tested using the programmer controller to set conditions for typical days during the annual period. The transient characteristics of its performance including the hot water consumption and reheating were included in all calculations and the yearly performance was modeled. The heat generated from the mCHP is plotted in fig. 6 . The temperature line illustrates the increase of the heat load when the hot water consumption occurs. This 
additional heat load is met by the auxiliary burner. It can be seen from fig. 6 that the total heat generation for approximately two hour period is equal to $11.5 \mathrm{~kW}_{\text {th }}$.

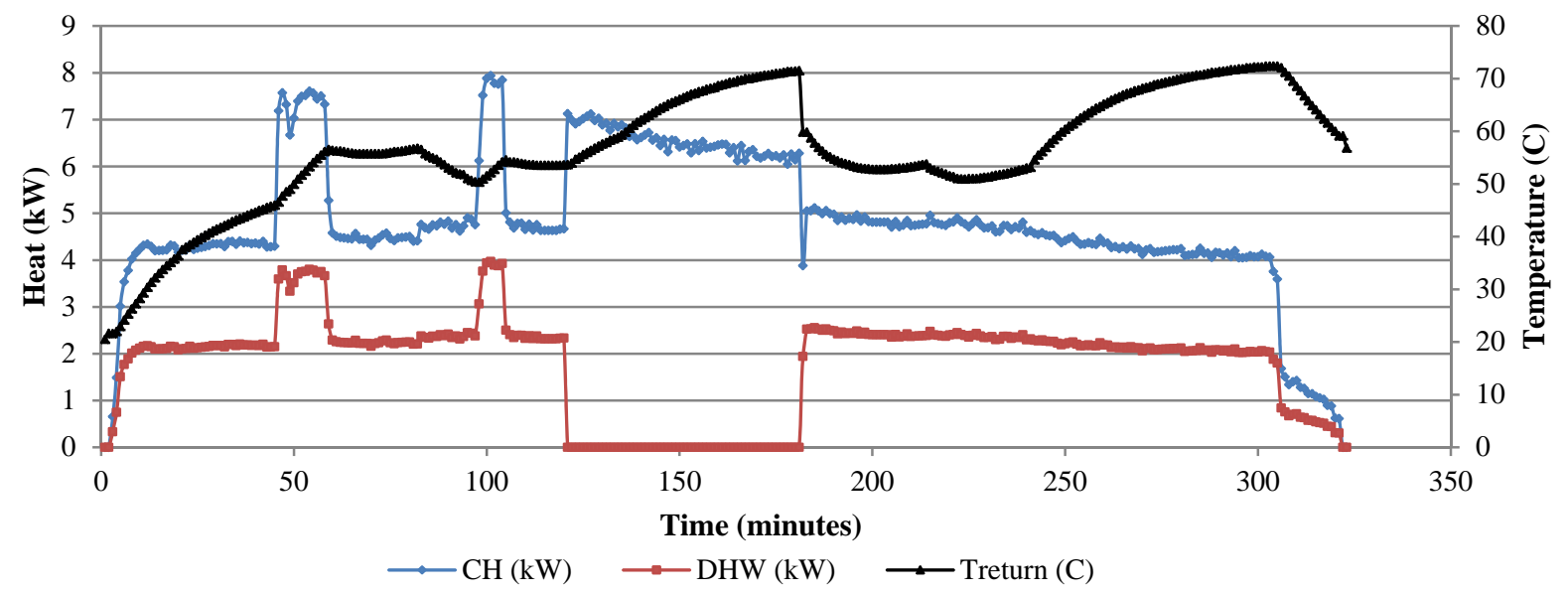

Fig. 6. Heat generation during the evening of a winter weekday

The annual performance of the mCHP compared to the dynamic simulation results of the conventional heating system is presented in table 3. The price of the mCHP unit and condensing boiler installed is about $£ 3500$ and $£ 750$, respectively. The simple payback period is calculated taking into account the difference in the capital cost, fuel consumption and the feed-in tariff.

Table 3. Annual performance of MCHP compared to a dynamically modeled conventional system.

\begin{tabular}{lc}
\hline Heating Plant & $\mathrm{mCHP}$ \\
\hline Annual monetary savings & $16 \%$ \\
Annual carbon savings & $0.17 \%$ \\
Simple Payback Period & 8 years \\
\hline
\end{tabular}

\section{Conclusions}

The feasibility study demonstrates that the mCHP compared to a condensing boiler in conventional domestic energy scenario can provide annual monetary benefits of up to $16 \%$ (taking into account new feed-in tariff, difference in the fuel consumption and assuming the same level of maintenance costs).

The performance of the mCHP is enhanced by a hot water consumption. This additional heat load caused the cooling water temperature to drop at around $50{ }^{\circ} \mathrm{C}$ where condensation is believed to take effect. This improved the mCHP thermal efficiency from $66 \%$ to $73 \%$. This improvement however was associated with marginal carbon savings $(0.17 \%)$ compared to a conventional energy scenario. This is believed to be caused by the low electrical and thermal efficiencies of the particular unit along with the electricity generated during the pre-heating period which is not consumed and therefore does not displace any grid electricity. To support this conclusion, research on the previous Whispergen Mk III mCHP unit [9] with 10\% higher overall efficiency indicated higher carbon saving potential. The difference between the current results and those obtained by RETScreen is believed to be due the the deficiencies in electricity demand modeling, energy pricing variations and the thermal efficiency of the mCHP varying with the heat demand. 


\section{References}

[1] Reacock, A., Newborough, M. (2008) Effect of Heat Saving Measures on the $\mathrm{CO}_{2}$ Savings Attributable to micro- Combined heat and Power ( $\mu \mathrm{CHP}$ ) Systems in UK Dwellings. Energy, 33 p. 601-612

[2] Thomas, B. (2008) Benchmark Testing of Micro-CHP Units. Applied Thermal Engineering, 28 p. 2049-2054

[3] Dorer, V., Weber, A. (2009) Energy and $\mathrm{CO}_{2}$ Emissions Performance Assessment of Residential micro-cogeneration Systems with Dynamic Whole-Building Simulation Programs. Energy Conversion and Management, 50 p. 648-657

[4] Hawkes, A., Leach, M. (2004). Impacts of Temporal Precision IN Optimisation Modelling of micro-Combined Heat and Power. Energy, 30 p. 1759-1779

[5] Combined Heat \& Power (Cogeneration) Project analysis. Available at: http://www.retscreen.net/ang/tools_and_other_algorithms.php\#a3. Date accessed: 24 January 2011

[6] Design Builder EnergyPlus Simulation Documentation. Available at: http://www.designbuilder.co.uk/component/option,com_docman/task,cat_view/gid,20/Ite mid,30/. Date accessed: 24 January 2011

[7] Voorspools, K. R., D'haeseleer, W.D. (2003). The Impact of the Implementation of Cogeneration in a Given Energetic Context. IEEE Transactions on Energy Conversion, 18(1) p.135-141

[8] Oda, T., Akisawa, A. and Kashiwagi T. (2004). A Theoretical Evaluation of a Cogeneration System's Total Energy Efficiency Considering Fluctuation in Heat and Power Demands. World Renewable Energy Congress VIII (WREC 2004)

[9] Veitch, D. C. G., Mahkamov, K. (2009). Assessment of Economical and Ecological Benefits from Deployment of a Domestic CHP Unit Based on its Experimental Performance. In: Proceedings of Institute of Mechanical Engineers, 223, Part A: Journal of Power and Energy

[10] Newborough, M., Augood, P. (1999). Demand-Side Management Opportunities for the UK Domestic Sector. IEE Proceedings: Generation Transmission and Distribution, 146(3) P. 283-293

[11]Carbon Trust. Micro CHP Accelerator. Interim report

[12] Reacock, A., Newborough, M. (2005). Impact of micro-CHP on Domestic Sector $\mathrm{CO}_{2}$ Emissions. Applied Thermal Engineering, 25 p. 2653-2676

[13] Introducing the Feed-in Tariff Scheme. Available at: http://www.ofgem.gov.uk/Media/FactSheets/Documents1/fitfs_energy\%20prices\%20upd ate\%20FS.pdf. Date accessed: 24 January 2011 